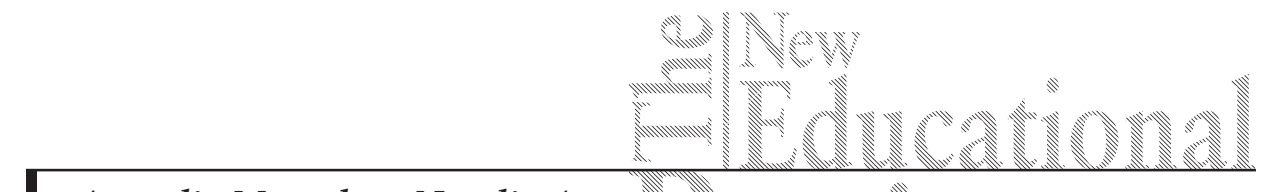

Anatoliy Merenkov, Natalia Antonove

\title{
Problems of Social Adaptation of International Students in Russia
}

DOI: 10.15804/tner.2015.41.3.10

\begin{abstract}
The article discusses a range of common problems faced by international students while studying in Russia, drawing on the example of Ural Federal University (Ekaterinburg). Analysis of the sociological data has shown that international students have to deal with the following adaptation barriers: organizational barriers which students face when joining the educational process; socio-cultural barriers which mostly stem from the lack of language proficiency; getting accustomed to daily routines of living on the campus; informational barriers caused by a low awareness of the conditions of life and studying in Russia (Russian cultural norms and values, the climate of the Urals, etc.). The article reveals a correlation between the specificity of the countries international students come from and the main stages of their adaptation, providing guidelines for improvement of international student support at Ural Federal University.
\end{abstract}

Keywords: international students, adaptation, adaptation of international students, Ural Federal University

\section{Introduction}

In the modern world international educational contacts are developing rapidly, opening access to higher education abroad for more and more young people. According to the Federal State Statistics Service, in 2010 there were 145,900 international students studying in Russia; this accounts for about $4 \%$ of the total 
number of international students in the world (Statistics Digest). According to forecasts, international student mobility will reach 5.8 million people in 2020 and eight million by 2025 (A. Torkunov, 2013). In the 2014/2015 academic year, Ural Federal University (UrFU) admitted about 300 international students. At the moment there are representatives of 36 countries studying at UrFU. The growth in the number of international students, however, raises issues relating to their successful adaptation to the new environment, to the different culture, and to the conditions of living in one of Russia’s largest cities.

\section{Methodological Framework}

Social adaptation is a special type of transformation of behavioural stereotypes during the process of a person's socialization in a foreign cultural environment, of her or him getting used to the norms and rules determining the lifestyle of the host community. What is more interesting is that this process involves certain changes in the host culture itself since the newcomers are likely to demonstrate behaviour forms and patterns which can seem strange to local residents and which provoke all sorts of reactions in their own behaviour and thinking.

Adaptation is a form of the subject's active reaction to the environment. It is targeted at changing the objectively existing structures as well as the subject's personality potential (P.M. Kozyreva, 2011, p. 25). We believe that there are always specific difficulties arising during the process of mutual transformation of orientations and attitudes of the subjects involved. These difficulties stem from the clash with their native cultures and norms, which determine their usual behaviour (A. Furnham, L. Tresize, 1983, pp. 365-370; I.K.K. Jensen, J.V. Jensen, 1983, pp. 371-377; F. T. L. Leong, E. L. Chou, 1996, pp. 210-242). The process of socialization means that the person acquires a number of orientations and attitudes shared by many social or ethnic groups along with some more specific and individual traits, characteristic only of a particular culture. Mingling with representatives of different cultures, on the one hand, shows that there are some common notions about what is an appropriate behaviour and what is not, thus creating conditions for a certain consensus but, on the other hand, the differences in stereotypes cause predicaments in achieving the desired results. This leads to hidden and open conflicts preventing individuals from adapting to the social groups with which they are interacting.

The level of adaptation of international students is determined by their lifestyle in the host country. The central processes here are: mastering the new requirements imposed on their work in lectures and seminars, on their success in assignments 
and course papers, and on their performance at tests and exams. Each country has its own ways of organizing the educational process, which are determined by the state educational standards, traditions, and styles of communication between instructors, university administrations and students.

Firstly, it means that international students will probably have to give up some forms of behaviour they are used to in their home country. Secondly, they will have to learn some new strategies, e.g., the procedures for working with different educational materials. International students face specific challenges which they have to deal with through personal effort, although sometimes there can also be some external factors affecting the situation. A special role in this process is played by the academic community and their readiness to be flexible towards satisfying the needs of international students (M. Cortazzi, L. Jin, 1997, pp. 196-219; P. Prescott, M. Hellsten, 2005, pp. 75-95; J. Ryan, 2000).

Proficiency in Russian is one of the crucial factors of international students' adaptation: they tend to demonstrate different levels of language fluency. There can be considerable psychological difficulties related to these students' language problems; these become apparent when the students are trying to communicate with their teachers, groupmates, and people in public places. Language competency is one of the most essential conditions for integration into the host community (A. Furnham, 1993, pp. 91-109).

Each country has its own cultural features of everyday lifestyle. Living on the campus, international students have to master some local cultural nuances, e.g., buying and cooking food and interacting with their roommates. Sometimes these students have to give up some elements of their national everyday culture and acquire new skills and habits necessary for their fitting in with the new environment.

In the process of adaptation they might also face problems of organizing their leisure time. What seems to be a customary thing when they are at home may cause a negative reaction of the local population in Russia. Therefore, it is essential that they should find out more about the leisure time activities and patterns of behaviour characteristic of Russian youth, UrFU students in particular. Moreover, they should gain some experience in terms of organizing their leisure time based upon the local cultural nuances. Finally, representatives of Russian culture should also be encouraged to get acquainted with the traditions of international students' native cultures.

Life in a foreign country often includes communication situations involving unknown people in the street, transport, shops, or theatres; this means that international students should learn the patterns of behaviour that do not provoke any 
negative reactions on the part of local people. This task is assisted by adjustment to the local patterns of communication in public places.

In general, the process of international students' adaptation depends on the number and quality of contacts they manage to establish and maintain in their everyday life (S. Bochner, 1986, pp. 5-44.) and the resulting formation of networks (S. Bochner, B. McLeod, A. Lin, 1977, 277-97; A. Furnham, N. Alibhai, 1985, pp. 709-722).

All these typical spheres of everyday interaction require a certain degree of self-development, self-education, and self-improvement. International students' acceptance of the foreign culture, their willingness to establish contacts with local people, and to learn a foreign language (Russian) serve as a valuable incentive for their successful adaptation (P.S. Heikinheimo, J.C.M. Shute, 1986, pp. 399-406). In this case getting a sound higher education in Russia, in Ekaterinburg, at UrFU will bring the highest possible results, which will ensure these graduates' both successful career and professional growth at home. At least this is what all the university staff seek to achieve by encouraging international students to adjust to their studies, to everyday life, and to leisure in the host country.

\section{Results and Discussion}

In 2014 and 2015 we carried out several sociological surveys in order to identify the main problems of adaptation faced by international students while studying at UrFU and living in Russia. These surveys involved students from such countries as Mongolia, Thailand, Korea, China, Japan, Palestine and some ex-Soviet republics: Ukraine, Kazakhstan, Azerbaijan, Uzbekistan, and Tajikistan. The questionnaire survey covered 320 students pursuing Bachelor's degrees (from the second to the fourth years of study) and 54 Master's students majoring in different subjects. The method of in-depth interviewing was also used to find out the opinions of 34 freshmen. In total, the survey embraced 218 female and 190 male students.

\subsection{Problems of educational adaptation of international students}

The primary adaptation problem, the most important, is lack of fluency in the Russian language. $61 \%$ of the students pointed out that it was the main impediment in their adaptation process and only every fourth student was sure that their speaking and writing skills in Russian were good enough. The problem with the language of the host community is a typical one, since studying in a foreign country always requires a good level of foreign language fluency. International students 
study in the same groups as those of the local population and lecturers are not required to know the language of the countries international students come from.

The study has reinforced our assumption that students from ex-Soviet countries know the Russian language better, which substantially enhances the process of their becoming accustomed to the local norms of everyday life and leisure.

Table 1. Russian language proficiency of international students (\%)

\begin{tabular}{lcc}
\hline Indicators & $\begin{array}{c}\text { Countries } \\
\text { of the former } \\
\text { Soviet Union }\end{array}$ & $\begin{array}{c}\text { Other } \\
\text { countries }\end{array}$ \\
\hline $\begin{array}{l}\text { I can read but I have difficulties with understanding the spoken } \\
\text { language }\end{array}$ & 10 & 25 \\
\hline I read and understand the spoken language & 28 & 23 \\
\hline I read and understand the spoken language & 55 & 38 \\
\hline I have just started learning Russian & 7 & 14 \\
\hline
\end{tabular}

Apart from language learning, the adaptation process is also affected by how motivated these students are to obtain a professional education in Russia. After graduating from school or getting their Bachelor's degree, young people may be made to go to Russia following the order of their government. A positive orientation towards active adaptation to studying in such new conditions may be unsuccessful in these circumstances. Such persons would consider themselves victims of circumstances and would have to review their negative stereotypes in relation to Russia. A conscious choice to study at a Russian university encourages international students to mobilize all their internal reserves in order to overcome any problems they face in the adaptation process.

The survey results show that about a quarter of the students from countries further abroad have come to Russia because they were ordered to do so. Their governments stipulated that they should gain the skills necessary for working with Russian technology. $18 \%$ of such students pointed out that they did not have other options apart from studying in Russia.

At the same time, $56 \%$ of the students who came to Russia from ex-Soviet countries said that they had really meant to study in Russia and had intentionally chosen a large, reputable university. Their main reason was that in the Soviet period their relatives or acquaintances received their education in Russia and maintained favourable memories of that time. People with such experience recall Russia as a place where one can get a high-quality education, which will ensure a successful 
career in the future. This group of international students demonstrated a positive attitude towards professional training in Russia, which enabled them to adapt to new conditions more efficiently.

Therefore, it should be noted that the knowledge students have about the country they are going to study in has a significant impact on their adaptation to the new environment.

Table 2. Knowledge of Russia before coming to study at UrFU (\%)

\begin{tabular}{lcc}
\hline Indicators & $\begin{array}{c}\text { Countries } \\
\text { of the former } \\
\text { Soviet Union }\end{array}$ & $\begin{array}{c}\text { Other } \\
\text { countries }\end{array}$ \\
\hline Main stages in the history of Russia & 54 & 20 \\
\hline Contemporary political and economic situation in Russia & 36 & 10 \\
\hline Organization of the education process in Russian universities & 52 & 11 \\
\hline Organization of students' daily life and housing & 16 & 11 \\
\hline Curriculum content & 10 & 14 \\
\hline Rules of communication with local residents in public places & 18 & 7 \\
\hline Shopping etiquette & 50 & 14 \\
\hline Communication with representatives of different ethnic groups & 18 & 2 \\
\hline Knew very little & 10 & 38 \\
\hline
\end{tabular}

Most of the students coming from far abroad know very little about Russia. Their teachers did not pay any attention to Russian history and culture either at school or at the university preparation course. Their limited knowledge about their receiving country is a factor which makes their lives considerably more difficult in the adaptation period. They have to learn by their mistakes; these stem from a lack of socio-cultural preparation. This inevitably causes problems between international students and their groupmates, with local residents in public places, at hospitals, and in leisure areas. These students may face psychological problems of adjusting to the lifestyle of a new, foreign community.

Another negative factor is that the overwhelming majority of international students comes from Thailand, China, and Japan and know little about the way the educational process is organized in Russian universities. As a result, they find it hard to get accustomed to such work formats as seminars or to prepare themselves for tutorials and to take their exams. Therefore, their learning performance in the first years is worse than that of the students who come from the ex-Soviet countries. 


\subsection{Problems of international students' adaptation in everyday life and in leisure}

International students' daily routines and leisure times tend to be the spheres where they face many adaptive challenges. Most of these problems are related to these students finding it hard to organize their everyday lives on the campus (this was pointed out by $46 \%$ of the respondents); as well as to the need to understand and abide by the rules of interacting with the administration (15\%) and with their neighbours (22\%). However, after some time, these students start adopting some local habits and including them in their daily practices: e.g., in drinking and eating practices (tea with lemon and sugar, or hot water with honey; eating pickled cucumbers) and in their style of dressing (wearing revealing clothes). These changes are more likely to occur among the students coming from European and African countries.

At the same time, international students preserve the national behavioural patterns which they acquired in early childhood; these manifest themselves primarily in their food habits. Students choose dishes from their national cuisine, which they cook themselves using spices sent from home. Canteens, cafés, and restaurants are not very popular among international students since they find them too expensive. Every third respondent mentioned high food prices and every fourth described their material status by saying: 'I only have enough money to buy food'.

Studying international students' leisure time make-up, it was found that this sphere has one single structure shared by all young people studying at the university. It is built around such activities as preparation for classes, recreation, and socializing with friends (in particular, via the Internet). $68 \%$ of the respondents like to spend their free time at the computer; $51 \%$ enjoy listening to their favourite music. About $40 \%$ constantly keep in touch with their friends and relatives at home via social networks. Russian students living on the campus organize their leisure time in the same manner. In the process of studying and living together, these two groups of students start sharing common interests and the process of their communication is characterized by friendliness ( $23 \%$ of the international students) and willingness to help (38\%).

At the same time, international students' adaptive processes tend to be more complicated because of conflicts with strangers in the street (35\%), with shop assistants, and with ticket inspectors on public transport (28\%). According to international students, these situations happen because they are immediately identified as representatives of ethnic groups unfamiliar to the wider Russian population.

However, the analysis of the survey results has shown that by their third or fourth year most international students $(70 \%)$ feel comfortable at the university 
and in public places. They hardly ever come into conflict with the host community, they do not require any help from the university staff and they engage in active leisure pursuits, going to the cinema and theatre.

\subsection{Barriers and stages of international students' social adaptation}

The research has shown that there are barriers to the social adaptation of international students. These barriers are defined as a complex of factors preventing students from mastering the norms which would enable them to organize their studies and extra-curricular activities effectively in order to achieve the desired performance results.

The following social adaptation barriers were identified: firstly, organizational barriers, related to the organization of international students' studies, their extra-curricular activities, and everyday life. The main problem areas are connected with the distribution of instructional hours in the curriculum, methodological, material and technical support of the educational process, and the housing conditions.

Secondly, there are economic barriers related to the financial well-being and security of student-migrants. This issue has been pointed out by $26 \%$ of the respondents.

Thirdly, there are socio-cultural barriers, which include problems related to the migrants' national and ethnic identity, their fluency in Russian, and their everyday behavioural and leisure patterns. Learning Russian is fundamental to international students' adjustment to the foreign environment: for $60 \%$ of the respondents, communication in the foreign language appears to be the toughest challenge in their adaptation process, while $8 \%$ believe that they have succeeded in mastering the skills of oral and written speech. Although international students accept the values and norms of the student subculture in their everyday life, they also adhere to their national and ethnic customs and traditions, which can cause additional difficulties. For instance, every fifth respondent mentioned the lack of opportunities for cooking their national dishes.

Finally, there are information barriers, stemming from the lack of information, or rejection, of information about the new social environment, its norms and values; this increases the social distance between the local population and the migrant and, in turn, causes their mutual alienation. $42 \%$ of the respondents claimed that they are aware of the nuances of communication with various ethnic groups living in Russia, but they still face difficulties in communicating with the locals and in understanding them. 
Coping with these issues depends on the following factors: the early adaptation stage begins in the students' motherland, in our opinion, and is related to the structure of their motivation to study in a foreign country. If their motivation is based on their desire to get a high-quality education, then the future student will be studying the peculiarities of the Russian education system, searching for information about the customs and traditions of Russian people in general and, more specifically, those of Russian students. 33\% of the respondents tried to follow this strategy. Every fifth respondent was searching for information about the housing conditions, the rules or regulations of living on campus, etc.

The next stage of adaptation, which can be defined as primary, starts after entering a Russian university. On average, it lasts from three months to one year. At this stage, international students get acquainted with the new social environment: they are actively mastering the language and observing the behaviour of local students during their studies and in everyday life. International students tend to communicate with their groupmates, especially with those who live in the same dormitory, and with their countrymen and countrywomen.

This stage takes significantly less time if an international student has already mastered the intermediate level of the Russian language by the time he or she arrives in the country (that is, they can read and understand spoken speech). As a rule, students from the former USSR pass this stage 1.5-2 times faster than those coming from Asia and Africa.

In order to move to the next stage, that of secondary adaptation, students should accumulate knowledge about Russia: its history, culture, patterns of communication between the sexes, and communication norms to be followed when interacting with the local population. At this stage international students understand and accept the key elements of the system of values of the new environment. This stage can last for a few months or up to four or five years. As a result of this progression, international students' integration into the new community, and their social status, is secured. Active interaction with the university staff and with Russian students as representatives of the host community enables international students to go more quickly through this phase.

Measurement of adaptive efficiency at this stage can be done by analyzing the following objective indicators: academic progress, participation in social and academic events, having Russian friends, the level of active recreation and leisure. There are also subjective measures: social well-being, satisfaction with the educational process, efficacy of housing conditions, and leisure time organization, confidence in personal security, no fears of any kind, etc. 
In this study, a system of subjective indicators was used to find out that the majority of the students (70\%) in their senior years (third or fourth year students) feel quite comfortable both within and outside the university. They hardly ever face any conflicts with the host community and do not need any help from the university administration; they enjoy active pastimes, and visit cinemas and theatres. The secondary adaptation stage lasts approximately three years.

\section{Conclusion}

To enhance the adaptation of international students in Russia it is necessary, firstly, to improve the system of teaching Russian in preparatory courses or in the countries where most students come from. Secondly, it is essential to introduce special country study courses to raise international students' awareness of Russian customs and traditions and the principles of cross-cultural communication at the university, on the campus, and in public places. Thirdly, it is essential to create conditions for providing individual counselling and support services for each international student, especially for those who have to cope with serious adaptation problems in their studies, everyday life, or leisure. Successful adaptation is vital for raising the efficiency of professional training and for the formation of a positive attitude towards Russia, the country where these students are being educated.

\section{Acknowledgments}

The authors would like to acknowledge the contribution made by Ural Federal University (the First President of Russia, B.N.Yeltsin), where the research was carried out.

\section{References}

Bochner, S. (1986). The Social Psychology of Cross-Cultural Relations. In: Cultures in Contact: Studies in Cross-Cultural Interaction. ed. S. Bochner, (pp. 5-44). Oxford: Pergamon.1986.

Bochner, S., B. McLeod, and A. Lin. (1977). Friendship Patterns of Overseas Students: A Functional Model. International Journal of Psychology 12: 277-97.

Cortazzi, M. and Jin, L. (1999). Cultural Mirrors: Materials and Methods in the EFL classrooms. In: Culture in Second Language Teaching and Learning ed. E. Hinkel (pp. 196-219). Cambridge: Cambridge University Press. 
Furnham, A. (1993). Communicating in Foreign Lands: The Cause, Consequences and Cures of Culture Shock. Language, Culture and Curriculum 6: 91-109.

Furnham A. and Alibhai N. (1985). The Friendship Networks of Foreign Students: A Replication and Extension of the Functional Model. International Journal of Psychology 20: 709-722.

Furnham, A. and Tresize, L. (1983). The Mental Health of Foreign Students. Social Science and Medicine 17: 365-370.

Heikinheimo, P.S. and Shute, J.C.M. (1986). The Adaptation of Foreign Students: Student Views and Institutional Implications. Journal of College Student Personnel 27 (5): 399-406.

Jensen, I.K.K. and Jensen, J.V. (1983). Cross Cultural Encounters: The Newly Arrived Asian Student. College Student Journal 17 (4): 371-377.

Kozyreva P.M. (2011). Social Adaptation of the Russian Population in the Post-Soviet Period . Social Studies 6: 24-36.

Leong, F.T.L., \& Chou, E.L. (1996). Counseling International Students. In: Counseling across cultures eds P. B. Pedersen, J. G. Drauguns, et al., (4th ed., pp. 210-242). Newbury Park, CA: Sage.

Prescott, P. and Hellsten, M. (2005). Hanging Together Even with Non-Native Speakers: The International Student Transition Experience. In: Internationalizing Higher Education: Critical Explorations of Pedagogy and Policy eds P. Ninnes \& M. Hellsten, (pp. 75-95). Hong Kong: Comparative Education Research Centre, HKU.

Ryan, J. (2000). A Guide to Teaching International Students. Oxford: Oxford Centre for Staff and Learning Development.

Torkunov A. (2013). Education as a 'Soft Power' Tool in the International Policy of Russia. Russian Committee for Foreign Affairs [Electronic resource]. International Policy of Russia. Analytics. Retrieved 27.02.2013, from http://russiancouncil.ru/inner/?id_4=1467\#8 